\title{
The Use of ICT in Education: a survey of schools in Europe
}

Patricia Wastiau, Roger Blamire, Caroline Kearney, Valerie Quittre, Eva Van de Gaer \& Christian Monseur

\section{Introduction}

The Survey of Schools: ICT in education was commissioned in 2011 by the European Commission Directorate General Communications Networks, Content and Technology to benchmark access, use of and attitudes to ICT in schools in the EU27, Croatia, Iceland, Norway and Turkey. It is one of a series in the EU's cross-sector benchmarking activities comparing national progress towards the Digital Agenda for Europe and EU2020 goals (EU Growth strategy for the coming decade)The Survey was conducted in partnership between European Schoolnet and the University of Liège (Service d'Approches Quantitatives des faits éducatifs, Department of Education $)^{1}$. It is the first European survey on the topic to be conducted online and to include students directly. Work on the survey took place between January 2011 and November 2012, with data collection in autumn 2011. This article presents its main findings based on over 190,000 questionnaire answers from students, teachers and head teachers.

\section{Analytical Framework}

Despite substantial funding for technology in schools and its stated importance in achieving national and European targets, there is a lack of reliable comparative data and indicators to support evidence-based policies (Pelgrum 2009; See also Biagi \& Loi in this issue pp. 28-42). The Survey of Schools: ICT in Education was designed to provide a more solid evidence base on the topic.

Across a range of international studies and reports a broad consensus is emerging on the domains for which indicators on the provision, use and impact of learning technologies and ICT policy initiatives in schools are needed. This work and the priorities formulated by the European Commission in the terms of reference for the Survey were used to define the following areas where indicators would be produced:

- Schools' ICT infrastructure (desktop computer; mobile devices such as laptops, notebooks, tablets, smartphones, etc.; broadband; school website, email addresses, virtual learning environment, etc.; deployment of equipment in classrooms, computer labs, libraries, etc.; maintenance). Infrastructure features in all definitions of the areas for which indicators on ICT in education are needed (Scheuermann \& Pedro, 2009); it is a basic condition, necessary but not sufficient, for any use to happen.

- Teachers' and students' access to ICT at school (years of experience using ICT at school, \% of time, frequency) and ICT-based activities organised by teachers and performed by students during lessons (frequency; type of activities; digital resources used). The case for the introduction of these two areas is made by Johannessen (in Scheuermann \& Pedro, 2009) and has been integrated in the 
Survey to better identify and quantify basic components that are more related to outputs - not in terms of achievement or competence (out of the scope of the present Survey) but of access, organisation, frequency and context of use, as well as the nature of ICT-based activities;

- Teachers' and students' declared confidence in their digital competences (operational skills, social media skills, safe and responsible Internet use) and training (participation, content and modalities). Although measuring digital competence was outside the scope of the investigation, an indicator of it was brought into the Survey by looking at the above areas in relation to the plea for ICT indicators to focus on outcomes and achievements (Erstad, Kikis, Scheuermann \& Villalba, in Scheuermann \& Pedro, 2009);

- School strategy and leadership (policies about ICT use in teaching and learning and in subjects; discussion about ICT use at whole-school level; time for teachers to collaborate and network; incentives to reward ICT use; innovation policy, etc.); the inclusion of this area also reflects recent work by the experts mentioned above which underlines the importance of school leadership for ICT to be adopted and fully used in teaching and learning by the whole school community (Erstad, Kikis, Scheuermann and Villalba, in Scheuermann \& Pedro, 2009);

- Opinions and attitudes of school heads, teachers and students (ICT relevance for different learning processes; impact on learning, achievement and motivation).

\section{Survey Methodology}

\section{Sampling Design}

The Survey collected data from schools (school heads), classrooms (teachers), and students at grade 4 (ISCED ${ }^{2}$ level 1 ; primary level of education), grade 8 (ISCED level 2; lower secondary level of education) and grade 11 (ISCED level 3; upper secondary level of education, general and vocational). Unlike the two previous surveys $^{3}$ on ICT, the Survey in schools: ICT in education had a student questionnaire component. Heads of schools with students in these grades, teachers teaching them and the students themselves were surveyed, the students only at grades 8 and 11 .

The international sample design framework is a stratified two-stage cluster sample design.

- In the first stage, schools were stratified, explicitly and/or implicitly, and selected with probabilities according to their size. Replacement schools were identified in advance in case a school refused to take part.

- In the second stage, one class was randomly selected within the sampled and participating schools, and all the students in the selected class were surveyed. Classes were selected with equal probabilities within schools.

Within schools, a simple random sample of one class was drawn from the list of possible classes at the target grade entered online by a school coordinator nominated by the head teacher. The definition of 'possible classes' depended on the level. At ISCED level 1, they are all those with target grade students. The teacher responsible for the class was in the teacher target population; if more than one teacher shared responsibility, one of the teachers was randomly 
selected. At ISCED 2 and ISCED 3 level, the possible classes were defined as the learning groups of students for the language of instruction (i.e. a class learning English in England, German in Austria, Italian in Italy, etc.). At ISCED level 2 and ISCED level 3, all mathematics, science, and language teachers who teach any student in the sampled class belong to the teacher target population. At ISCED level 3 vocational education, if there were no language classes, an administrative unit was chosen.

\section{Implementation Process}

The ministries of education in each country were asked to nominate a national coordinator (NC) and provide access to the most recent version of their official school databases. Samples of schools and replacement schools were randomly selected in each country for each grade.

\section{Administration Process}

The three survey questionnaires were translated into the official language(s) of the participating countries and made available to respondents in the appropriate language.

Administration of the survey was online. The school coordinator was emailed the URL of questionnaires, IDs and passwords and asked to distribute them to the school head and the selected teachers and students.

\section{Data Analysis}

After data cleaning and weighting and non-response adjustments, data were processed and standard errors calculated.

Some of the items in the school head, teacher and student questionnaires were designed to be used in analyses as single items (e.g. gender), but most were designed to be combined in some way in order to measure latent constructs that could not be observed directly. For these items, transformations or scaling procedures were used to construct meaningful indices (varimax rotation with SAS software, Cronbach alpha's calculation, etc.).

A two-step cluster analysis method (in SPSS software) was used to identify groups of students, teachers, and schools that resemble each other on a number of preselected variables. When determining the number of clusters, not only statistical criteria were taken into account (best fit), but also criteria of interpretability and similarity across the different grades, i.e. solutions that were interpretable and that fitted each grade.

The Survey findings are based on 156,634 questionnaire answers from students, 24,522 from teachers and 10,137 from head teachers in 27 countries $^{4}$ collected between September and December 2011.

\section{First Part of the Survey Findings: 'State of the Art' indicators}

\section{ICT Infrastructure in Schools}

Laptop and tablet computers ${ }^{5}$ and mobile phones are increasingly seen as useful in education (Prensky, 2004), offering portability and choice as to when and where to use them. A literature review of UK research on the topic (Savill-Smith and Kent, 2003 cited in Condie, 2007) states that in order for a specific device to be used optimally, certain technical and organisational conditions must be fulfilled 0 . A 
tablet was found to be best used together with a wireless network and a wireless data projector which enabled it to be moved around between pupils in class, something which is difficult to organise with laptops that are physically connected to an interactive whiteboard (IWB) for example. There is also a growing body of evidence on the impact of IWBs on learning. Research from the UK (Underwood, 2009) investigated the use of IWBs and learning platforms as a lever for change. Whilst IWBs are motivating for students and facilitate cross-school use of ICT, they are not strongly linked to transformational pedagogies or learning (Wastiau 2010).

One area of investigation in the Survey is whether a trend is observed that moves away from fixed installations of computers in labs, classrooms or other locations towards mobile learning devices. Another is the availability of online learning environments and their characteristics as well as other support devices enabling overall efficient functioning, e.g. availability of projectors, wireless and broadband connections.

The Survey findings paint a picture of students and teachers with unprecedented access to educational technology: there are around twice as many computers per 100 students in secondary schools than in 2006, laptop computers are available in classrooms, and broadband is almost ubiquitous in schools $(95 \%$ of schools compared to $65-75 \%$ in 2006). There are now between three and seven students per computer on average in the EU; computers are more often located in the classroom, even if still frequently found in computer labs. Laptops, tablets and netbooks are becoming pervasive, but only in some countries (See Bocconi et al. in this issue pp. 113-130). In these countries, the impact of such a trend can be expected to be positive on learning processes and students' competence; the literature review previously mentioned (Savill-Smith and Kent, 2003 cited in Condie, 2007) revealed that personal digital assistants (PDAs) helped to increase student motivation, develop organisational skills, encourage responsibility, facilitate independent and collaborative learning and were useful as reference and assessment tools for tracking pupils' progress (See Redecker \& Johannessen in this issue pp. 79-96). The Survey findings show that, on average in the EU, interactive whiteboards are present in approximately one in three classrooms (over 100 students per IWB), as well as data projectors (50 per 'beamer' as they are sometimes called). More than 9 out of ten students are in schools with broadband, at most commonly between 2 to 30 mbps.

According to the Survey results, at EU level on average, between 25 and 35\% of students in grades 4 and 8 , and around $50 \%$ of students in grade 11 are in highly equipped schools, i.e. with fast broadband (10 mbps or more) and high connectedness. The percentages of such schools differ enormously between countries. At least $80 \%$ of students in grades 4 and 8 are in highly digitally equipped schools with fast broadband and relatively high connectedness in Denmark, Finland, Norway and Sweden where almost all students in grade 11 are in such highly equipped schools. Conversely, less than $20 \%$ of students in grade 4 and less than $10 \%$ in grade 8 are in such schools in around half the countries surveyed (Bulgaria, Croatia, Greece, Hungary, Italy, Slovakia, Slovenia, Poland, Romania and Turkey); the situation in these countries improves at grade 11 , but to a large extent only in Croatia and Slovenia where $60 \%$ to $80 \%$ of students are in highly equipped schools. These findings are presented in Figure 1 . 
a

$0 \%$

$20 \%$

$40 \%$

$60 \%$

$80 \%$

$100 \%$

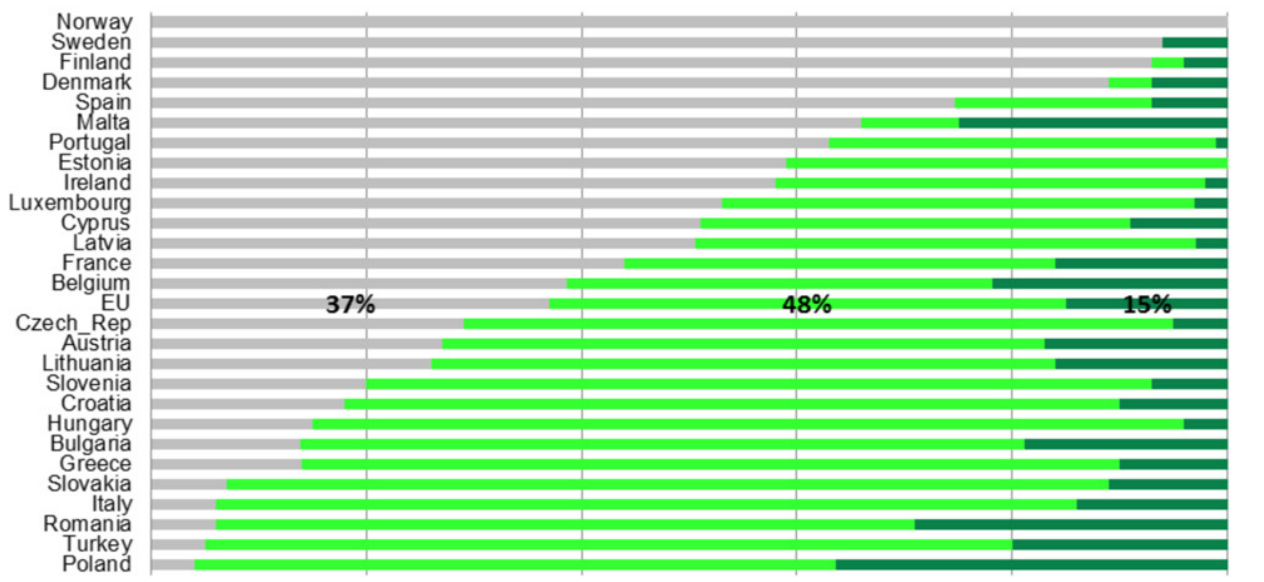

$=$ Type 1 -Type 2 -Type 3

Type 1= Highly digitally equipped school, i.e. high equipment level, fast broadband, high connectedness (school website, virtual learning environment, teachers and students email addresses, etc.)

Type 2: Partially digitally equipped school, i.e. lower equipment level compared to type 1 schools, less than 10 mbps or no broadband, some connectedness

Type 3: Lowly digitally equipped school, i.e. as type 2 but with no connectedness

b

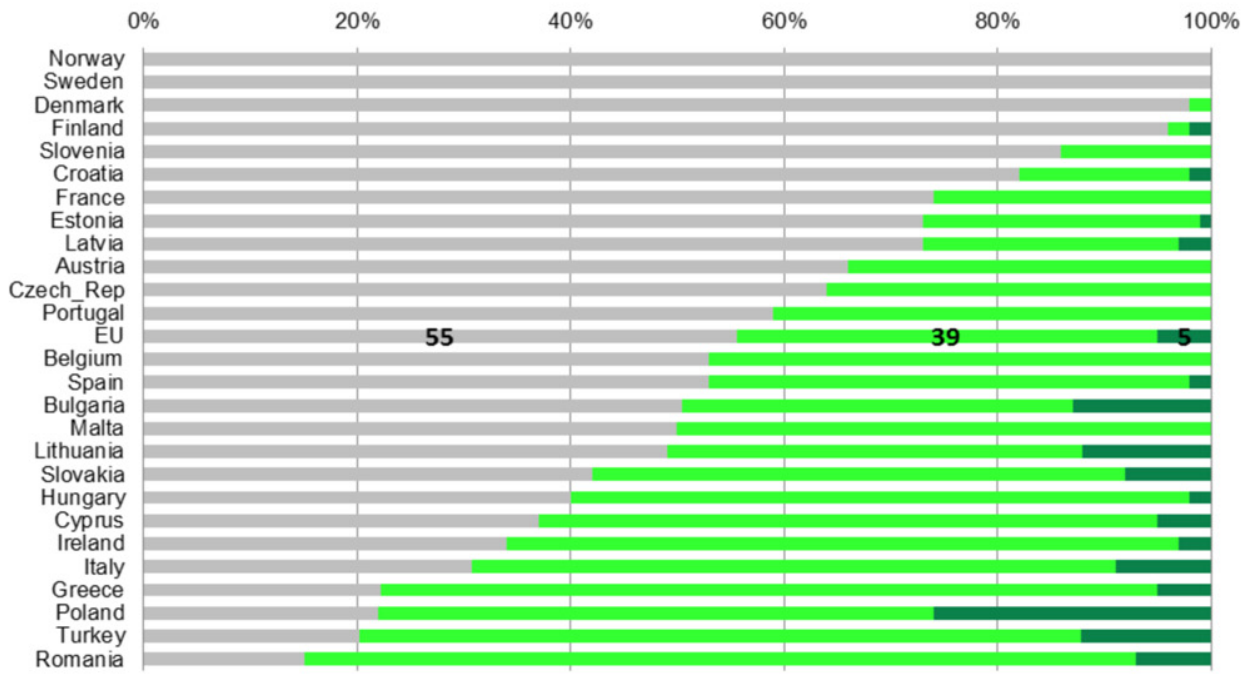

"Type 1 =Type 2 -Type 3

FIGURE 1. Percentages of students at grade 4 (Fig. 1a) and grade 11 general (Fig. 1b) by school type in terms of equipment

Source: country and EU level, 2011-12. 
Even so, the survey also reveals that school heads and teachers consider that insufficient ICT equipment (especially interactive white boards and laptops) is the major obstacle to ICT use. Inhibitors are not the same across countries.

Interestingly, the Survey did not find any overall relationship between high levels of infrastructure provision as defined above and student and teacher use, confidence and attitudes. This confirms a key finding of the international comparative study of pedagogy and ICT use in schools, SITES 2006 (Law, Pelgrum, \& Plomp, 2008), conducted by the IEA and which focused on the role of ICT in teaching and learning in mathematics and science classrooms. It showed that provision, access and connectivity do not, in themselves, lead to ICT use in learning and teaching.

\section{Students' and Teachers' Confidence in their Digital Competence and Frequency of ICT-based Learning Activities}

Research over the past 15 years has demonstrated the significant influence of teacher competence on student achievement (Owston, 2006). It is therefore important for all teachers to have the necessary knowledge and skills to integrate ICT in their daily teaching practice in order to maximise their ability to help to improve students' digital competence. The digital competence here involves the confident and critical use of Information Society Technology (IST) for work, leisure and communication. It is underpinned by basic skills in ICT, i.e. the use of computers to retrieve, store, produce, present and exchange information, and to communicate and participate in collaborative networks via the Internet (European Commission, 2007).

Research shows that there is a relation between teachers' digital competence and their use of ICT in the classroom. Hence, participation in professional development activities can significantly influence their ICT use (Fredriksson et al., 2008; Valiente, 2010). Teachers prefer informal methods of training, blended training and training that relates to real classroom settings (Balanskat et al., 2006), and collaboration between teachers is an efficient way for such professional development to happen (Bacigalupo \& Cachia 2011). We also know from research in this area that more experience in using technologies is positively related to the acquisition of students' digital skills and their confidence in using these tools (OECD, 2010). More generally, incoming teachers have not been sufficiently trained in the pedagogical use of ICT (OECD, 2008; Starkey, 2010). They are generally more traditional users of the Internet and lack knowledge in how to exploit social media tools for learning (MMB, 2008). Evidence also suggests that social media approaches can facilitate technological, pedagogical and organisational innovation in teaching and learning, thus contributing to the modernisation of systems and institutions to meet the challenges of the 21 st century (Redecker et al., 2009).

The Survey of Schools: ICT in education investigates teachers' and students' frequency of ICT use and ICT-based activities during lessons, as well as their confidence in their respective digital competences, and the relationship between both. The findings reveal that most have been familiar with ICT at school for a few years but still mainly use it to prepare their teaching. Only a few use it - but still to a limited extent - to work with students during lessons, and even less frequently to communicate with parents or divide students' work between school and home in new ways. The overall frequency of use of different types of ICTbased activities in class declared by teachers is several times a month on average at EU level, while students declare undertaking ICT-based activities between 
several times a month and never or almost never. The higher frequency declared by teachers could be explained by the lack of equipment accessible to all students in the classroom and by the teacher-centred approach — as opposed to the student-centred one - that still prevails in many teaching and learning environments. Digital resources such as exercise software, online tests and quizzes, data logging tools, and computer simulations are still very rarely used by students during lessons. Their ICT-based activities related to learning at home are more frequent than ICT activities at school. This finding underlines both the extent of intentional learning taking place outside school and students' interest in spontaneous self-directed learning.

The Survey results also show that teacher participation in ICT training for teaching and learning (T\&L) is rarely compulsory. At EU level, depending on the grade, only around $25-30 \%$ of students are taught by teachers for whom ICT training is compulsory. This is in contrast to teachers' interest in ICT shown in the Survey: around $70 \%$ of students at all grades are taught by teachers who have engaged in personal learning about ICT in their own time. Although online resources and networks are widely available in Europe, they are a relatively new way for teachers to engage in professional development, and only a minority of these opportunities are used by schools.

The Survey findings provide evidence that teachers who are confident in their digital skills and positive about ICT's impact on learning organise more frequent ICT-based activities with their students. They were asked to rate their level of confidence in their ability to perform 20 ICT-related tasks using a Likert scale ranging from 'none' to 'a lot'. By subjecting the data to factor analysis, two scales emerged from the 20 items. These included what had been categorised as operational skills and social media skills. Teachers' operational skills comprise production of text using word processing software; editing digital photos, movies or other graphics; editing online text containing Internet links and images; creating a database; using a spreadsheet to plot a graph; downloading and installing software on a computer, etc. Social media skills consist in the ability to participate in an online discussion forum, create and maintain blogs or websites and participate in social networks. Figure 2 presents the results in terms of mean scores on a scale from 1 to 4 ( 1 being 'none' and 4 being 'a lot'). Unsurprisingly, across countries, teachers consider themselves more confident in their operational skills than in their social media skills.

\begin{tabular}{|lr|r|r|r|r|}
\hline & Grade 4 & Grade 8 & Grade 11 gen. & Grade 11 voc. \\
Operational skills & 2,98 & 3 & 3,01 & 3,16 \\
Social media skills & 2,41 & 2,37 & 2,38 & 2,51 & \\
\hline
\end{tabular}

FIGURE 2. Teachers' confidence in their operational and social media skills Source: mean score on a scale from 1 - meaning 'not at all confident' - to 4 meaning 'a lot confident'; EU level; 2011-12.

Students were asked to rate their level of confidence in their ability to perform more than 24 ICT-related tasks according to a Likert scale ranging from 'not at all' to 'a lot'. Factor analysis of the data revealed four scales from the list of items. These included operational skills and social media skills (as found in the 
teachers'data and defined above) and two additional scales related to students' ability to use the Internet safely and responsibly. Safe use includes their confidence in their ability to protect their privacy and online reputation and respect those of others as well as their confidence in their ability to use the Internet to protect themselves against online bullying, spam and junk mail. Students' confidence in their ability to use the Internet responsibly is defined as the ability to judge the reliability of information found on the Internet; to identify online sources of reliable information; and to use information found on the Internet without plagiarising. At EU level on average, students who participated in the Survey considered they were very confident to use the Internet safely and less so in their social media skills (see Figure 3).

\begin{tabular}{|lr|r|r|r|}
\hline & Grade 8 & Grade 11 gen & Grade 11 voc & \\
Safe internet use & 2,98 & 3,16 & 2,98 & \\
Responsible internet use & 2,58 & 2,93 & 2,75 & \\
Operational skills & 2,63 & 2,88 & 2,78 & \\
Social media skills & 2,41 & 2,78 & 2,55 & \\
\hline
\end{tabular}

FIGURE 3. Students' confidence in their digital skills

Source: mean score on a scale from 1 - 'not at all confident' - to 4 - 'very confident'; EU level; 2011-12.

These findings reveal the efforts still to be engaged, both at students' and teachers' level, to develop their social media skills, considered by several pieces of research previously mentioned as one of the key components of $21^{\text {st }}$ century education.

\section{Second Part of Survey Findings: the exploratory part of the analysis}

\section{The Schools' Effect on Students' ICT Use and Activities During Lessons}

The Survey shows that both students and teachers have the highest frequency of ICT use and ICT-based activities during lessons when they are in schools that combine policies (defined in the Survey as associated with the existence of written policy statements) about ICT integration in T\&L generally speaking as well as in subject learning, using incentives (financial incentives, fewer teaching hours, competitions and prizes, training hours, additional ICT equipment for the classroom) to reward teachers using ICT, and implementing concrete support measures such as professional development and the provision of ICT coordinators. Interestingly, students in schools that focus on concrete support measures use ICT more frequently during lessons than those in schools with policies but no concrete support measures. Rather than reflecting a higher efficacy of concrete support measures compared to policies, this observation is more probably explained by the fact that policies are defined at central level in several education systems and were not necessarily reported by school heads at school level. Schools belonging to these two groups are defined in the Survey as digitally supportive schools.

On average across the EU countries covered by the Survey, 25-30\% of students are in digitally supportive schools with policies and concrete support measures. This percentage goes up to $40-50 \%$ (rather less in vocational education) if 
students in digitally supportive schools that mostly focus on concrete support measures are added. There are very large differences between countries: at least $50 \%$ of students - and many more in a few countries at grade 4 - are in digitally supportive schools (at several grades) with both policies and support measures in the Czech Republic, Denmark, Norway, and Slovenia, as well as in Bulgaria, Estonia, Ireland and Spain at grade 4; while only less than $10 \%$ of students are in such schools in Croatia (at grade 8), France (at grade 4) and Greece at grade 8 and 11 .

\section{The Teacher Factor in Students' Use of ICT for Learning}

Students' use of ICT for learning during lessons is related to teachers' confidence in their own ICT competences, their opinion about the relevance of ICT for T\&L and their access to ICT at school. The Survey shows that students ICT most frequently when they are taught by teachers with great confidence in their own digital competence (operational and social media skills) and in their ability to use the Internet safely and responsibly, with positive opinions about ICT use for T\&L, as well as facing few obstacles and having broad access to ICT infrastructure at school. These teachers are defined in the Survey as digitally confident and supportive teachers.

On average across the EU countries covered by the Survey, between 20-25\% of students are taught by digitally confident and supportive teachers having broad access to ICT and facing few obstacles to their use at school. Here again, there are great differences between countries. 30 to $50 \%$ of students at grade 4 and/or grade 8 are taught by such teachers in Bulgaria, Estonia, Ireland, Portugal, Slovakia, Slovenia and Sweden; conversely, less than $10 \%$ of students in the same grades are taught by such teachers in Austria, Belgium, Cyprus, France, Finland, Greece and Luxembourg. In grade 11 general education, more than $45 \%$ of students are taught by such teachers in Denmark, Luxembourg, Norway and Portugal; conversely, less than $10 \%$ of students are in this situation in Greece, Romania and Turkey.

Interestingly, students taught by teachers who are confident in their own ICT skills and positive about ICT use in T\&L but who have little access and face obstacles to its use report more frequent use of ICT during lessons than students taught by teachers with great access and few obstacles, but who are neither confident in their own digital competence nor positive about ICT use for T\&L. These findings show that confident and supportive teachers are needed to use ICT infrastructure effectively and exploit its potential and that they are able to make the best use of relatively poor ICT learning environments.

\section{The Effect of Students' ICT Use at School or Home on Confidence in Their Digital Competences}

A key finding of the Survey shows that, across the countries surveyed, students are more confident in their digital competences when they have great access to/use of ICT at home AND at school than students who have little access/use at school and high access/use at home, or little access/use at both ${ }^{6}$. Such confidence applies to students' operational ICT skills, social media skills, ability to use the Internet responsibly, and, to a slightly lesser extent, to use the Internet safely. These students are not only confident in their digital competences, but are also positive about the impact of using ICT in T\&L. Such students, with great access/use to 
ICT at home AND at school are defined in the Survey as digitally confident and supportive students.

Across the EU countries, on average $30-35 \%$ of students are digitally confident and supportive students. The highest percentage is found in Denmark at all grades and in Norway at grade 11 . Across the EU, the highest percentage is observed in grade 11 general education, suggesting there has been a particular focus on policies at that education level. Around $50 \%$ of students in grades 8 and 11 vocational education and down to $35 \%$ in grade 11 general education have great access/use at home but little access/use at school. Of particular concern is the fact that $18-28 \%$ of students, depending on the grade, have little access to/use of ICT both at home and at school.

Relationships between digitally supportive schools, digitally confident and supportive teachers, and digitally confident and supportive students

The Survey findings presented above indicate percentages of digitally supportive schools, digitally confident and supportive teachers and digitally confident and supportive students. Are there any relations between these? In other words, do educational systems with a high percentage of digitally supportive schools include a large percentage of digitally confident and supportive teachers or students, or the reverse? To answer these questions, correlation coefficients were computed at country level between these percentages. What follows illustrates the results at grade 11 in general education (the same analysis was made at grades 4, 8 and 11 in vocational education but is not presented here; the trend is similar throughout all grades, the only difference being its extent).

\section{Digitally Confident and Supportive Teachers and Digitally Supportive Schools}

To some extent (a correlation of 0.33 ), as the percentage of digitally supportive schools increases, so does that of digitally confident and supportive teachers. While there may be national or regional contexts that favour the development of digitally supportive schools and digitally confident and supportive teachers, the data do not allow us to affirm whether digitally supportive schools encourage teachers to become supportive or the reverse. A coefficient correlation does not, of course, prove a causal relationship, but simply confirms the numerical association between phenomena. In other words, where we find digitally supportive schools, we also find digitally confident and supportive teachers.

Although correlations are statistically significant at grades 4 and 11 vocational education, they are not at grades 8 and 11 general education. This is not surprising given the small size of the population concerned (the countries participating in the survey), but it does not prevent the trend from being mentioned.

Mapping of countries by percentages of students in digitally supportive schools and percentages of students taught by digitally confident and supportive teachers is presented in Figure 4. It shows that differences between countries are greater concerning percentages of students in digitally supportive schools than percentages of students taught by digitally confident and supportive teachers. Percentages of the latter are particularly high in Denmark and Norway at grade 11 in general education compared to other countries; analysing the data in the same way at each level in the survey reveals that percentages of students in digitally supportive schools are also high in both countries at all grades. 


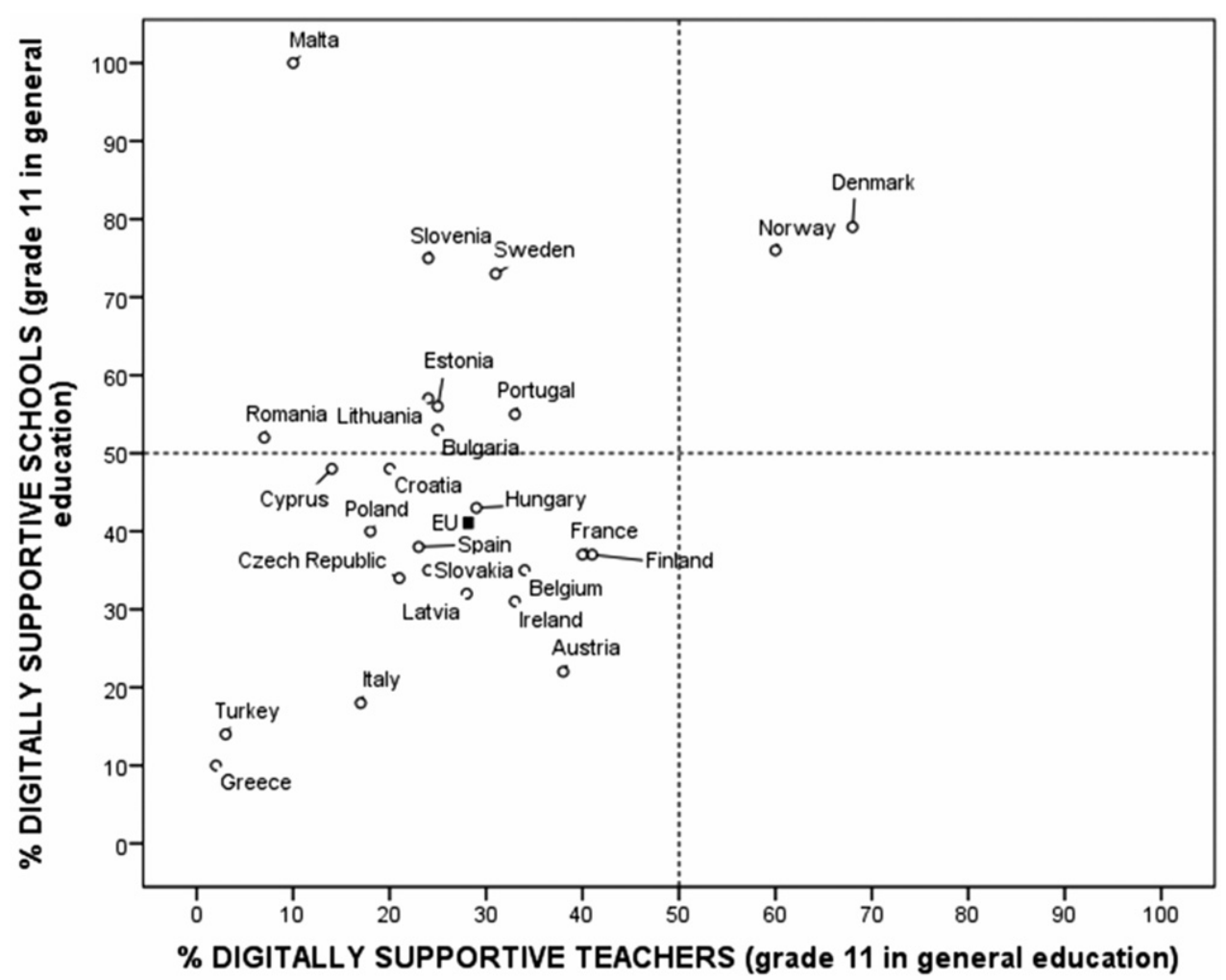

FIGURE 4. Digitally supportive schools and digitally confident and supportive teachers

\section{Digitally Confident and Supportive Students and Digitally Supportive Schools}

Mapping of countries by percentages of students in digitally supportive schools and percentages of digitally confident and supportive students is presented in Figure 5 . To quite a high degree ( 0.70 correlation), countries with a high percentage of digitally supportive schools also have a high percentage of digitally confident and supportive students; conversely relatively few digitally confident and supportive students can be found in countries with few digitally supportive schools. Here again, these correlations are statistically significant at grade 8 and 11 in vocational education but not at grade 11 in general education and the same remark as above applies.

\section{Digitally Confident and Supportive Students and Teachers}

Finally, a relation is also observed between digitally confident and supportive teachers and digitally confident and supportive students. To some extent $(0.43$ correlation), countries with a high percentage of digitally confident and supportive teachers are also countries with a high percentage of digitally confident and supportive students (even if the correlation is not statistically significant which, as mentioned previously, is not surprising because of the size of the population concerned here, i.e. the number of participating countries). 


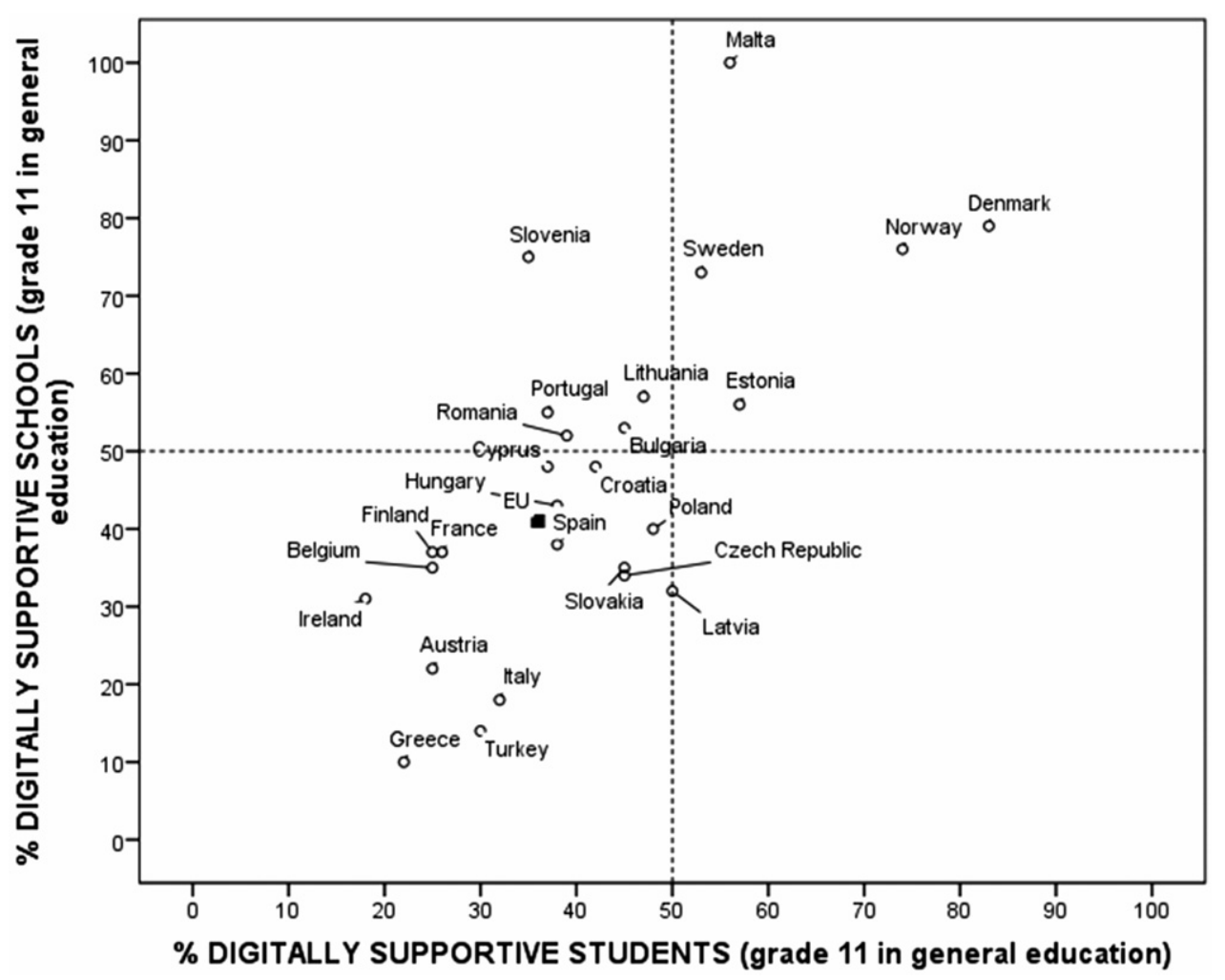

FIGURE 5. Digitally supportive schools and digitally confident and supportive students

Mapping of countries according to percentages of students taught by digitally confident and supportive teachers and percentages of digitally confident and supportive students is presented in Figure 6. It shows that, in most cases and in all countries, percentages of students taught by digitally confident and supportive teachers are below 50\%, but percentages of digitally confident and positive students reach much higher values in around a third of the countries, especially in Estonia, Malta, and Sweden. Only in Denmark and Norway are percentages above $50 \%$.

\section{Policy Making Implications}

\section{Focus support on teachers}

Policy makers at central/national, regional, local and school level should massively invest in teachers' professional development in order to increase the number of digitally confident and positive teachers throughout Europe. Effective professional development can transform positive attitudes and sufficiency in ICT provision into effective and sustained classroom practice. The opportunity to develop expertise and a $21^{\text {st }}$ century identity for the profession should also be exploited by teachers on their own, all the more so given the interest shown by a large majority of them in learning about ICT in their own time. The Survey also showed that, depending on the school context, obstacles to the use of ICT related to lack of competence and pedagogical models, unclear goals for using ICT or a lack of 


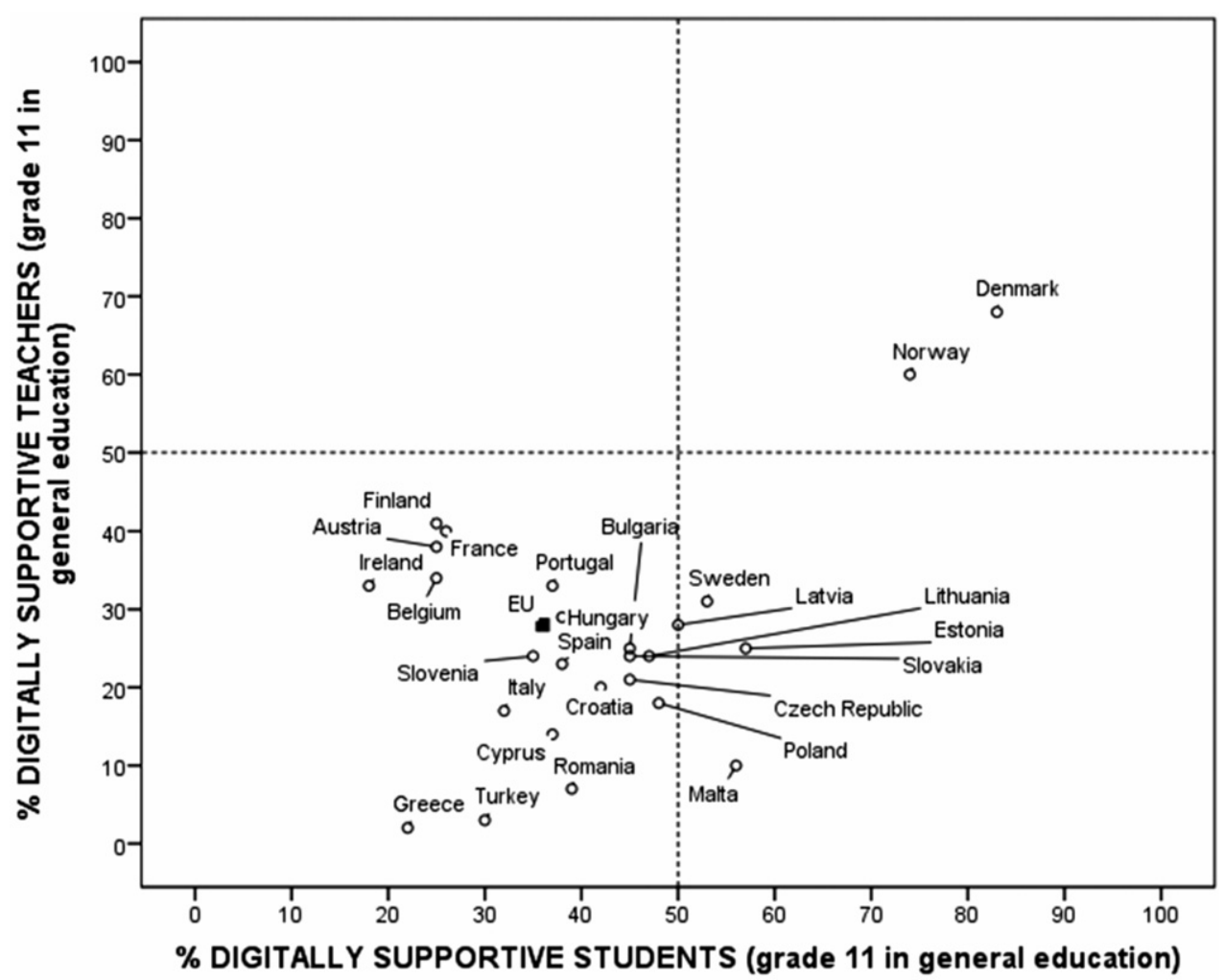

FIGURE 6. Digitally confident and supportive teachers and students

consensus about it. Therefore regular discussions with teaching staff should not only help to increase consensus about ICT use for T\&L at whole school level, but also be a starting point for peer learning exchanges between teachers and stimulate new ways of 'on the job' professional development. A particular focus should be put on capacity building in the area of new patterns of teacher professional development through online learning communities and other approaches closely integrated into teachers' daily practice (informal methods, blended learning, teacher and school networking on a local/regional basis, etc.), all of which are not much used according to the Survey findings. These more recent professional development models should also integrate teaching and learning activities, showing teachers how ICT can be fully integrated to support efficient learning. Policy makers should also devote attention to the creation and dissemination of good quality digital learning resources in order to increase their use by teachers and students during lessons.

More than $70 \%$ of teachers surveyed at all grades expressed a positive or very positive opinion about the relevance and positive impact of ICT to support different students' learning processes (working collectively, autonomously, practising, etc.) and objectives (motivation transversal skills, higher order thinking skills, etc.). This overwhelmingly positive opinion of the latter presents an opportunity that should not be missed for teacher professional development to produce huge benefits and impact. In other words, there is no longer a need to convince teachers and school heads about the relevance of using ICT for T\&L, but the 


\section{European Fournal of Education, Part I}

need to equip teaching staff with the digitally based teaching competences and experience they need to transform positive opinions into efficient practice in the classroom.

Policies and actions defined at EU level to support a quantitative and qualitative increase in teacher professional development could usefully look at capacity building in the area of new patterns of professional development using the currently under-used approaches mentioned above. This action at EU level could identify the conditions for the best use of such types of scheme and how to mainstream them, more from the point of view of process-related than content aspects. EU actions in support of the production of evidence about which approach to use according to the objectives to be reached would contribute to better in-service teacher training provision and renewed initial teacher education.

Bring about inspiring school leadership and support infrastructure development where still needed

The findings of the Survey show that policies and actions relating to infrastructure provision are still needed if most students at all grades are to be in highly digitally equipped schools as defined above. These policies, focused on providing laptops (or tablets, netbooks, etc.) and interactive whiteboards, would help to overcome what is still considered by practitioners as the major obstacle to ICT use. Such policies are a matter of urgency in those countries that lag behind others. At EU level, supporting policies should take into account the very different levels and characteristics of infrastructure provision measured by the Survey depending on the country, developing diversified support actions suited to the most equipped education systems as well as to the less well-equipped ones.

The Survey findings also strongly support the idea that the goal of increasing students' - and teachers' - ICT use for T\&L during lessons can be reached through other types of action at whole-school level. Increasing the number of digitally supportive schools is then a complementary objective to be set in several countries, and urgently so in countries with very low percentages of such schools. Depending on the extent of autonomy given to schools, national, regional and local policy makers - and school heads more importantly in decentralised systems - would do well to define and implement policies on ICT integration in teaching and learning as well as in subjects, implement incentives to reward teaching staff using ICT in T\&L, introduce a change management programme, and — very importantly — provide daily support in the classroom thanks to readily available ICT coordinators. Rather than suggesting that there is a 'silver bullet' type of policy or intervention offering a panacea for supporting ICT use in T\&L at school level, the findings of the Survey show that it is a combination of several of the above policies and measures, articulated together in a systemic approach, that make the difference.

Boost the use of ICT at school to build students' confidence in their digital competence

The Survey findings underline the importance of developing ICT use during lessons in school for students to become more confident in their digital 
competence, regardless of the many opportunities some have to use ICT out of school, and even more fundamentally for those who still lack access to it at home. Increasing the amount of well-designed ICT-based activities in school is the best way to increase the number of digitally confident and supportive students.

Policy makers should also consider how to offer access/use to ICT at school to students who do not have access to/use at home. The survey findings make a case for strengthening public action at institutional, local, regional, national and European levels to boost ICT use at school as a means to reduce the gap between ICT use out of and in school - a gap identified many years ago but still persistent in 2012 - and give greater opportunities to about $30 \%$ of 16-year-old students who lack adequate home access to ICT to experience and benefit from it at school. ICT use at school should take account of differences in home access and patterns of use by students. The survey findings (e.g. the digitally confident and supportive student) reinforce those reported in Are the New Millennium Learners Making the Grade? (OECD, 2010): the digital divide in education goes beyond the issue of access to technology. A second digital divide separates those with the competences and skills to benefit from computer use from those who do not. These competences and skills are closely linked to students' economic, cultural and social capital (See Istance \& Kools in this issue, pp. 43-57).

\section{Conclusion}

The survey results point to a number of policy actions at all levels of the system to ensure optimal use of increasingly tight financial resources. European policies can play a major role to support all the above policies and actions needed to bring about a digital education system and increase the number of digitally supportive schools and digitally confident and supportive teachers and students by continuing to regularly monitor progress in all Member States. Particular attention should focus on countries where the effective use of ICT in T\&L still lags far behind education systems in other countries.

Patricia Wastiau, European Schoolnet, 61 rue de Trèves, 1040 Brussels, Belgium, patricia. wastiau@eun.org

Roger Blamire, European Schoolnet, 61 rue de Trèves, 1040 Brussels, Belgium, roger.blamire@eun.org

Caroline Kearney, European Schoolnet, 61 rue de Trèves, 1040 Brussels, Belgium, caroline.kearney@eun.org

Valérie Quittre, Service d'approches quantitatives des faits éducatifs (SAQFE), Département Education, Université de Liège, Boulevard du Rectorat, 54000 Liège, Belgium,V.Quittre@ulg.ac.be

Eva Van de Gaer, Service d'approches quantitatives des faits éducatifs (SAQFE), Département Education, Université de Liège, Boulevard du Rectorat, 54000 Liège, Belgium,eva.vandegaer@ond.vlaanderen.be

Christian Monseur, Service d'approches quantitatives des faits éducatifs (SAQFE), Département Education, Université de Liège, Boulevard du Rectorat, 54000 Liège, Belgium,cmonseur@ulg.ac.be 


\section{NOTES}

1. The University of Liège's partners were in charge of the whole sampling design, data cleaning and weighting, and statistical analysis (frequencies, correlations, scales development, cluster analysis). European Schoolnet designed the analytical framework, the questionnaires, and drafted the comments from the statistical analysis.

2. ISCED is the International Standard Classification in Education (ISCED-97) adopted in 1997 by the UNESCO General Conference.

3. eEurope 2002 - An Information Society For All - Action Plan prepared by the Council and the European Commission, 19-20 June 2000 http:// ec.europa.eu/information_society/eeurope/2002/action_plan/pdf/actionplan_ en.pdf

eEurope 2005 - An information society for all - An Action Plan, 21/22 June 2002 http://eur-lex.europa.eu/LexUriServ/LexUriServ.do?uri=COM:2002: 0263:FIN:EN:PDF

4. Due to the low schools participation rate in Germany, The Netherlands, the UK and Iceland, data concerning these countries were not considered representative enough to be included in the analysis.

5. Tablets or tablet computers can be defined as a personal mobile computer larger than a mobile phone integrated into a flat touch screen and primarily operated by touching the screen (Wikipedia).

6. The cluster analysis used to study the issue at stake did not identify a fourth group composed of students with great access/use at school and little access/ use at home.

\section{REFERENCES}

Balanskat, A., Blamire, R. \& Kefala, S. (2006) The ICT Impact Report. A Review of Studies of ICT Impact on Schools (Brussels, European Schoolnet).

Bacigalupo, M. \& CACHIA, R. (2011) Teacher Collaboration Networks in 2025. What is the Role of Teacher Networks for Professional Development in Europe? (Sevilla, JRC-IPTS).

European Commission (2007) The Key Competences for Lifelong Learning - A European Framework (annex of a Recommendation of the European Parliament and of the Council of 18 December 2006 on key competences for lifelong learning (Brussels, European Communities).

Fredriksson, U., Jedeskog, G. \& Plomb, T. (2008) Innovative use of ICT in schools based on the findings in ELFE project, Education E Information Technologies, 13, pp. 83-101.

Law, N., Pelgrum, W. J. \& Plomp, T. (Eds) (2008) Pedagogy and ICT Use in Schools around the World. Findings from the IEA International Comparative Studies Sites 2006 (Hong Kong, CERC-Springer).

MMB (2008) Digitale Schule — wie Lehrer Angebote im Internet nutzen (Institut für Medien- und Kompetenzforschung).

OECD (2008) ICT and Initial Teacher Training-research. Review Draft (Paris, OECD Publishing).

OECD (2010) Are the new Millennium Learners Making the Grade? Technology Use and Educational Performance in PISA (Paris, OECD Publishing). 
Owston, R., (2006) Teachers can make a difference: Professional development as a policy option for improving student learning with ICT. Paper prepared for the CEIRIS-Keris international Expert meeting on ICT and Educational Performance), South Korea, October 16-17, 2007.

Pelgrum, H. (2009) Study on Indicators of ICT in Primary and Secondary Education/IIPSE (Brussels, European Commission).

PRENSKY, M. (2004) Digital Game-based Learning (New-York, McGraw-Hill)

Redecker, C., Ala-Mutka, K., Bacigalupo, M., Ferrari, A. \& Punie, Y. (2009) Learning 2.0: The Impact of Web 2.0 Innovations on Education and Training in Europe (Sevilla, JRC-IPTS).

SCHEUERMANN \& PEDRO, F. (2009) Indicators, Criteria and Benchmarks for International Comparisons (Luxembourg, OPOCE).

SAVILl-SMITH, C. \& KENT, Ph. (2003) The use of palmtop computers for learning: a review of the literature, in: R. CONDIE \& B. MUNRO (2007) The Impact of ICT in Schools - A Landscape Review (Coventry, BECTA).

STARKEY, L. (2010) Teachers' pedagogical reasoning and action in the digital age, Teachers and Teaching: theory and practice, 16, pp. 233-244.

Underwood, J. (2009) The Impact of Digital Technology (Coventry, BECTA).

VAliEnte, O. (2010) 1-1 in Education: Current Practice, International Comparative Research Evidence and Policy Implications. OECD Education Working Papers, No. 44 (Paris, OECD Publishing).

WASTIAU, P. (2010) Virtual Learning Platforms in Europe: what can we learn from experience in Denmark, the United Kingdom and Spain? - A Comparative Overview (Paris/Brussels, Caisse des dépôts/European Schoolnet). 